\title{
Glutathione synthesis is essential for pollen germination in vitro
}

Bernd Zechmann ${ }^{1,2^{*}}$, Barbara E Koffler ${ }^{1}$ and Scott D Russell ${ }^{3}$

\begin{abstract}
Background: The antioxidant glutathione fulfills many important roles during plant development, growth and defense in the sporophyte, however the role of this important molecule in the gametophyte generation is largely unclear. Bioinformatic data indicate that critical control enzymes are negligibly transcribed in pollen and sperm cells. Therefore, we decided to investigate the role of glutathione synthesis for pollen germination in vitro in Arabidopsis thaliana accession Col-0 and in the glutathione deficient mutant pad2-1 and link it with glutathione status on the subcellular level.

Results: The depletion of glutathione by buthionine sulfoximine (BSO), an inhibitor of glutathione synthesis, reduced pollen germination rates to $2-5 \%$ compared to $71 \%$ germination in wildtype controls. The application of reduced glutathione $(\mathrm{GSH})$, together with $\mathrm{BSO}$, restored pollen germination and glutathione contents to control values, demonstrating that inhibition of glutathione synthesis is responsible for the decrease of pollen germination in vitro. The addition of indole-3-acetic acid (IAA) to media containing BSO restored pollen germination to control values, which demonstrated that glutathione depletion in pollen grains triggered disturbances in auxin metabolism which led to inhibition of pollen germination.
\end{abstract}

Conclusions: This study demonstrates that glutathione synthesis is essential for pollen germination in vitro and that glutathione depletion and auxin metabolism are linked in pollen germination and early elongation of the pollen tube, as IAA addition rescues glutathione deficient pollen.

Keywords: Arabidopsis auxin, gametophyte, glutathione, indole-3-acetic acid, pollen

\section{Background}

Glutathione is an important antioxidant and redox buffer in eukaryotes and most prokaryotes that fulfills many roles in plant metabolism and plant defense during abiotic and biotic stress conditions in the sporophyte [1], but its role remains largely unknown for the gametophyte. In the sporophyte, glutathione is involved in the detoxification of reactive oxygen species (ROS), redox signaling, the modulation of gene expression and in the regulation of enzymatic activities [extensively reviewed by 1]. Glutathione is also involved in the detoxification of xenobiotics, herbicides $[2,3]$ heavy metals such as cadmium [4-8], and protects proteins from oxidation by a process called glutathionylation [9-11]. The importance of glutathione for plant growth and development is highlighted by the observation that impaired

\footnotetext{
* Correspondence: bernd.zechmann@uni-graz.at

'University of Graz, Institute of Plant Sciences, Schubertstrasse 51, 8010 Graz, Austria

Full list of author information is available at the end of the article
}

glutathione synthesis correlates with growth defects [12,13], and that the complete absence of glutathione synthesis results in a lethal phenotype [14]. Additionally, the redox state of glutathione is also important for plant growth and development. In non-stressed plants it occurs mainly in its reduced form $(\mathrm{GSH})$, whereas during oxidative stress high amounts of oxidized glutathione (GSSG) can be formed. The occurrence of high amounts of GSSG correlates with reduced growth, dormancy, or cell death [15-17].

Glutathione synthesis takes place in two ATPdependent steps triggered by enzymes that are encoded by single genes in Arabidopsis [18]. In the first step cysteine is linked with glutamate to form $\gamma$-glutamylcysteine. This reaction is triggered by $\gamma$-glutamylcysteine synthetase (GSH1). In the second step, glycine is linked to $\gamma$-glutamylcysteine by glutathione synthetase (GSH2) to form the final product glutathione. In Arabidopsis, these two steps seem to take place exclusively in plastids and the cytosol, which are 
therefore considered as the main centers of glutathione synthesis [18]. In the sporophyte, transcripts of GSH1 and $\mathrm{GSH} 2$ and the final product, glutathione, can be found in all major plant parts and in all cell organelles at different concentrations (Additional files 1 and 2) [19,20]. According to immunohistochemistry and quantitative transmission electron microscopy, the highest levels of glutathione have been detected in mitochondria and the lowest in plastids. Vacuoles contained glutathione only under certain conditions (e.g. high sulfur soil contents, high amounts of oxidized glutathione) [21,22], whereas glutathione could not be detected in cell walls [20]. Although the role and subcellular distribution of glutathione in the sporophyte are well defined, the necessity and role of glutathione in the gametophyte remain largely unexamined. Bioinformatic data cast doubt on the importance of glutathione metabolism in the male gametophyte, as both GSH1 and GSH2 are transcribed at negligible levels in pollen and sperm cells (Additional files 1 and 2) $[23,24]$. Nevertheless, due to the apparent sensitivity of microspores to mitochondrial damage induced by chronic oxidative stress [25], we decided to investigate the necessity and localization of glutathione in the gametophyte in order to reveal strategies for pollen to cope with ROS during tube germination and elongation.

In the current study, we investigate whether glutathione is essential for pollen germination, and if so, whether such pools of glutathione depend on new synthesis or an existing glutathione pool available in the pollen grains before the start of germination. The subcellular distribution of glutathione will also reveal if glutathione is distributed equally or shows compartmentspecific adaptations as found in leaf and root cells [20].

In order to achieve this goal we studied pollen germination rates and the subcellular distribution of glutathione in pollen grains of wildtype plants treated with and without buthionine sulfoximine (BSO). BSO is known to inhibit the first enzyme of the glutathione synthesis pathway thus leading to a strong decrease in glutathione levels [26-31]. Additionally, we studied pollen germination rates and the subcellular distribution of glutathione in the pollen grains of the pad2-1 mutant, which has a mutation of the first enzyme of the glutathione synthetic pathway thus reducing the content of glutathione by $80 \%$ compared to the wildtype [19,32]. Differences in glutathione contents between the wildtype and the pad2-1 mutant should give detailed insight into the roles of temporary and permanent glutathione depletion on pollen germination in vitro.

\section{Results}

\section{Pollen germination}

Wildtype pollen grains showed a germination rate of $71 \%$ when grown on germination medium without GSH and BSO (Figure 1 and Figure 2). Treatment of $0.1 \mathrm{mM}$ BSO, which depletes glutathione, decreased pollen germination rate to about $5 \%$. To examine whether glutathione depletion may be linked with decreased levels of auxin, which is one of the most important plant

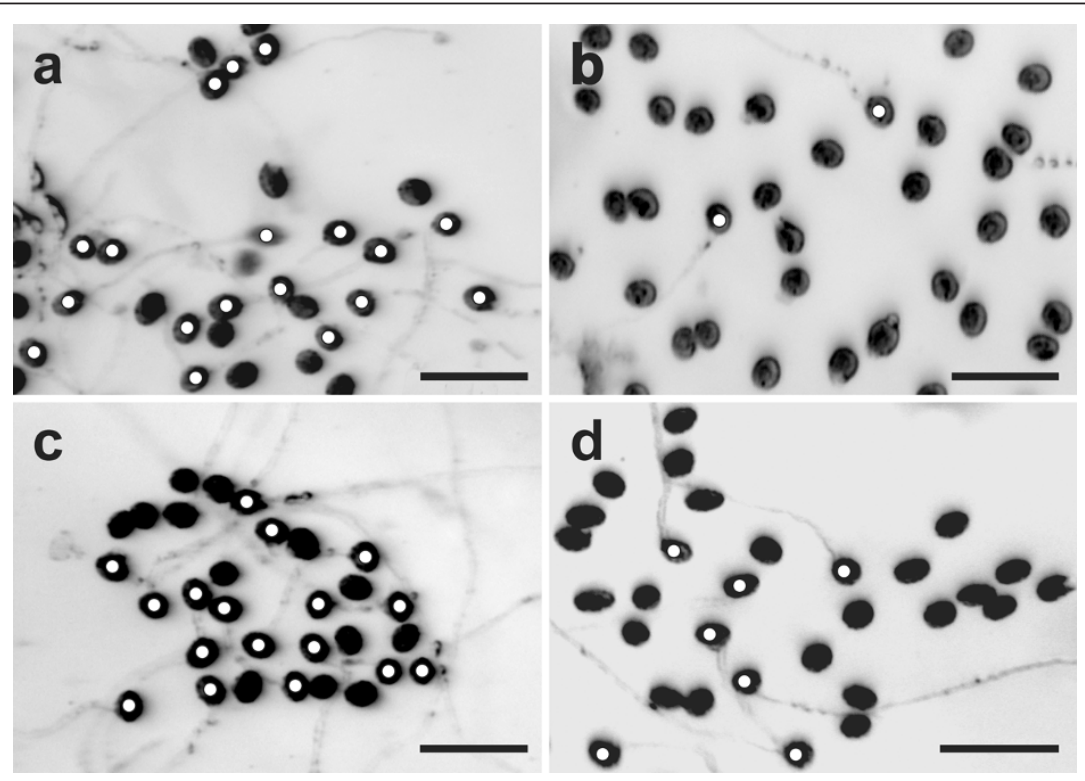

Figure 1 Images showing the effect of BSO and GSH treatment on pollen germination in Col-0. Light microscopical images show Arabidopsis thaliana accession Col-0 pollen grains after $16 \mathrm{~h}$ incubation on solidified pollen germination media containing (a) no GSH and BSO (control), (b) $0.1 \mathrm{mM} \mathrm{BSO}$, (c) $0.1 \mathrm{mM} \mathrm{BSO}$ and $1 \mathrm{mM} \mathrm{GSH}$, and (d) $0.1 \mathrm{mM} \mathrm{BSO}$ and $3 \mathrm{mM} \mathrm{GSH}$. Original images were inverted and germinating pollen grains were marked with white circles for better visualization. Bars $=100 \mu \mathrm{m}$. 


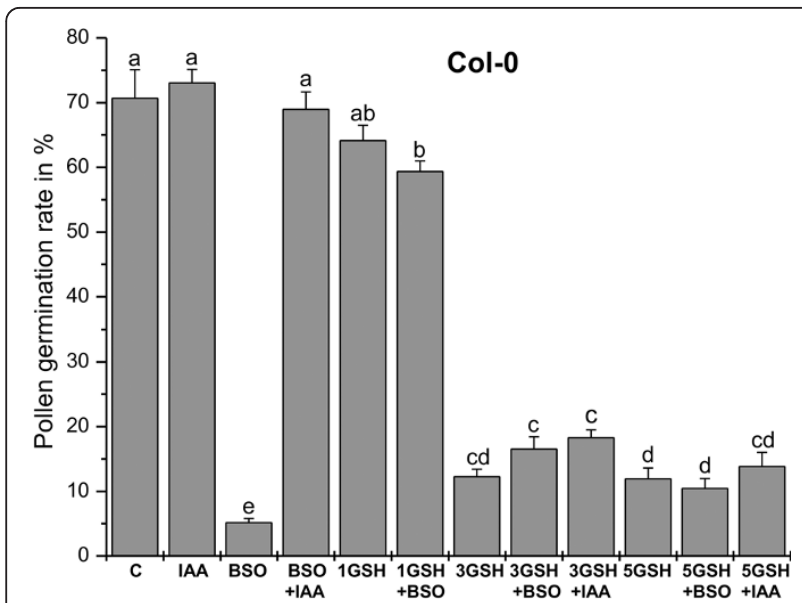

Figure 2 Statistical analysis of the effects of BSO, GSH, and IAA treatment on pollen germination rate in Col-0. Graph shows Arabidopsis thaliana accession Col-0 pollen germination rates (\%) after $16 \mathrm{~h}$ incubation on solidified pollen germination media containing different concentrations of BSO $(0.1 \mathrm{mM}), \mathrm{GSH}(1,3$, or 5 $\mathrm{mM})$ and IAA $(22.8 \mu \mathrm{M})$ for 16 hours. Data represent means and standard errors. Different lowercase letters indicate significant differences $(P<0.05)$ analyzed with the Kruskal-Wallis test followed by post-hoc comparison according to Conover. N > 2000 pollen grains per treatment from 3 or more independent experiments.

hormones for pollen tube growth [33,34], we have applied $22.8 \mu \mathrm{M}$ indole-3-acetic acid (IAA) together with BSO in the growth media. The addition of IAA to growth media containing BSO restored pollen germination rate to levels similar to the control (69\%; Figure 2 and Figure 3). Similar levels were reached (73\%) when pollen germination was performed on pollen germination media containing only IAA (Figure 2 and Figure 3 ). The addition of $1 \mathrm{mM} \mathrm{GSH}$ to the media containing 0.1 $\mathrm{mM}$ BSO restored pollen germination rate to $60 \%$. A similar rate (64\%) was found when wildtype pollen grains (without BSO) were allowed to germinate on media containing $1 \mathrm{mM}$ GSH. Pollen germination rate was reduced to $12 \%$ when higher concentrations of GSH ( $3 \mathrm{mM}$ and $5 \mathrm{mM}$ ) were added to the growth medium (Figure 2). A similar germination rate $(16 \%$ and $11 \%$, respectively) was observed after pollen grains were transferred onto pollen germination media containing $0.1 \mathrm{mM} \mathrm{BSO}$ and either $3 \mathrm{mM}$ or $5 \mathrm{mM} \mathrm{GSH}$ (Figure 1 and Figure 2). The addition of IAA to the pollen media containing $3 \mathrm{mM}$ and $5 \mathrm{mM}$ GSH did not significantly change pollen germination (Figure 2). Higher BSO concentrations $(1.5 \mathrm{mM}$ and $5 \mathrm{mM})$ had similar inhibitory effects on pollen germination rate as observed using media containing $0.1 \mathrm{mM}$ BSO (Additional file 3). Nevertheless, the addition of $1 \mathrm{mM} \mathrm{GSH}$ only partially restored pollen germination rate $(29 \%$ and $12 \%)$ when added to $1.5 \mathrm{mM}$ and $5 \mathrm{mM}$ BSO, respectively. The addition of $3 \mathrm{mM}$ GSH to pollen germination media containing $1.5 \mathrm{mM}$ and $5 \mathrm{mM}$ led to pollen germination at rates of $14 \%$ and $5 \%$, respectively (Additional file 3 ).

Pollen germination of the pad2-1 mutant was around $16 \%$ on medium without GSH and BSO (Figure 4 and Figure 5). Similar levels were reached (16\%) when pollen germination was performed on pollen germination

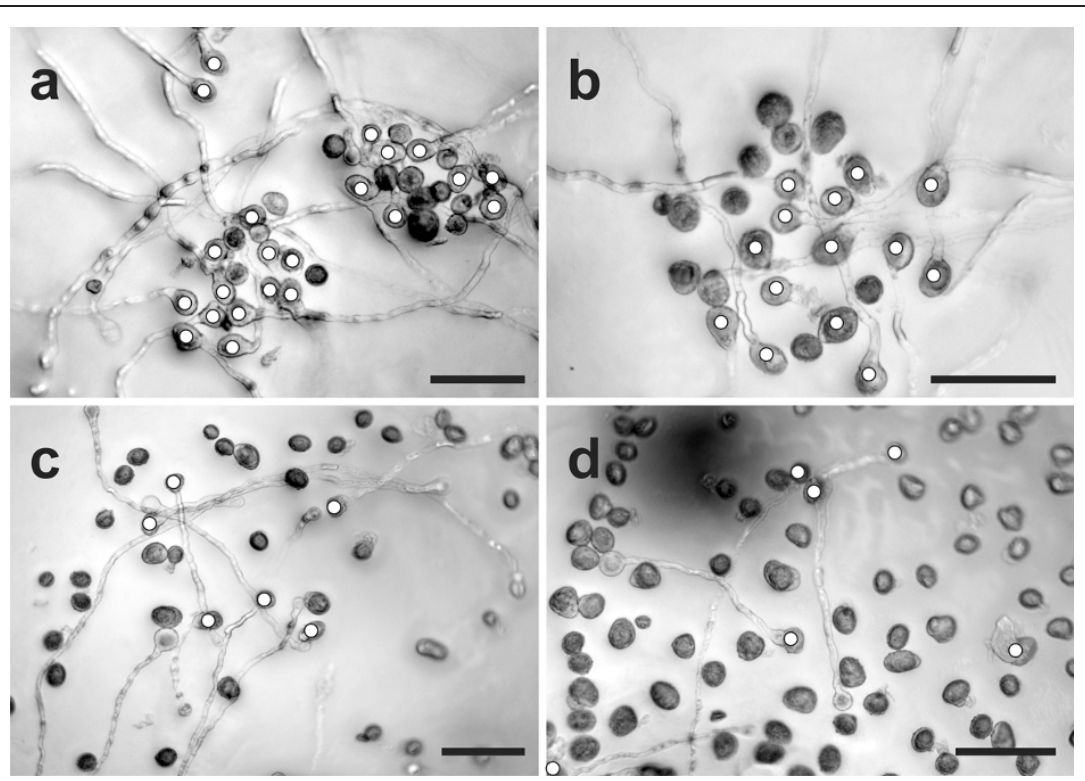

Figure 3 Images showing the effect of IAA treatment on pollen germination. Light microscopical images show pollen grains of Arabidopsis thaliana accession Col-0 ( $a, b)$ and the pad2-1 mutant $(c, d)$ after $16 \mathrm{~h}$ incubation on solidified pollen germination media containing a, c) 22.8 $\mu \mathrm{M}$ IAA and b, d) $0.1 \mathrm{mM} \mathrm{BSO}$ and $22.8 \mu \mathrm{M}$ IAA. Pollen grains were marked with white circles for better visualization. Bars $=100 \mu \mathrm{m}$. 


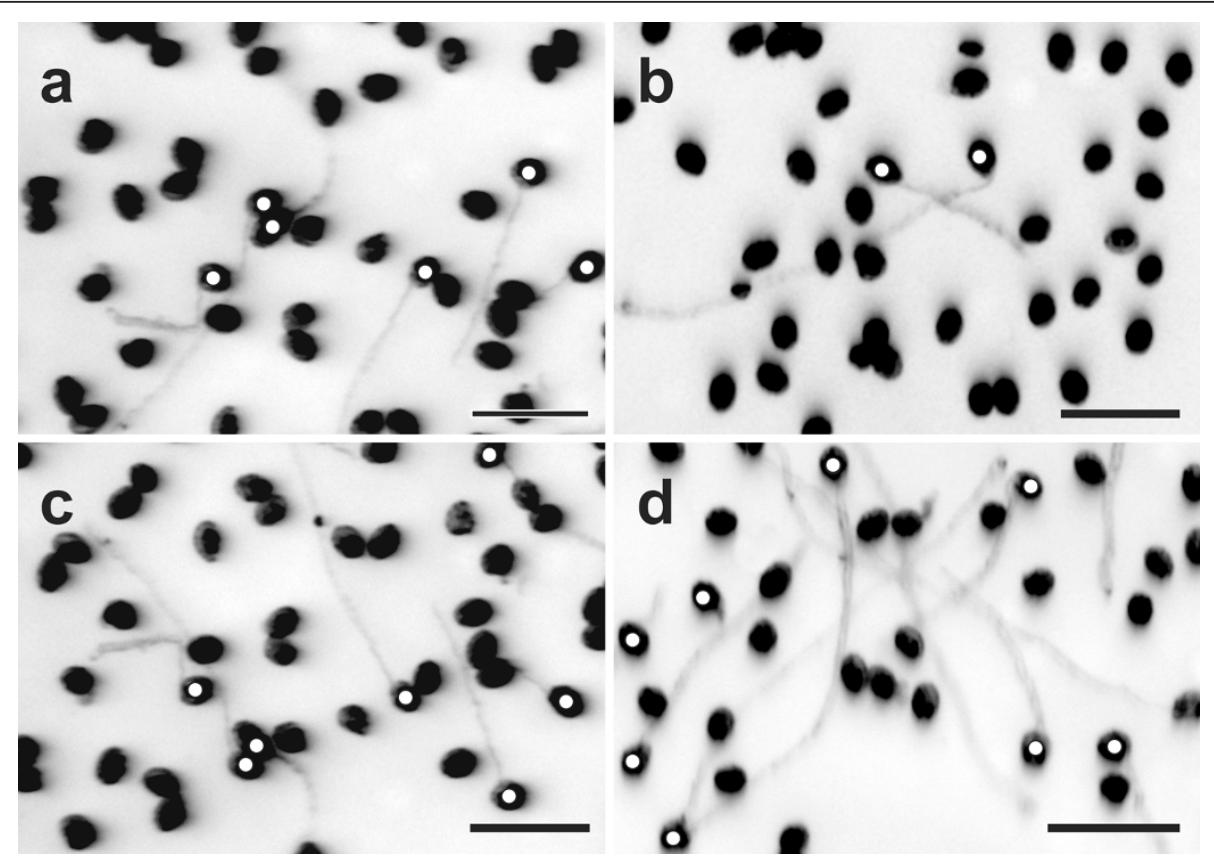

Figure 4 Images showing the effects of BSO and GSH treatment on pollen germination in pad2-1. Light microscopical images show pollen grains of the Arabidopsis thaliana mutant pad2-1 after $16 \mathrm{~h}$ incubation on solidified pollen germination media containing (a) no GSH and BSO (control), (b) $0.1 \mathrm{mM} \mathrm{BSO}$, (c) $0.1 \mathrm{mM} \mathrm{BSO}$ and $1 \mathrm{mM} \mathrm{GSH}$, and (d) $0.1 \mathrm{mM} \mathrm{BSO}$ and $3 \mathrm{mM} \mathrm{GSH}$. Original images were inverted and germinating pollen grains were marked with white circles for better visualization. Bars $=100 \mu \mathrm{m}$.

media containing IAA (Figure 3 and Figure 5). Treatment of $0.1 \mathrm{mM}$ BSO decreased pollen germination rate to $6 \%$. The addition of auxin to growth media containing $\mathrm{BSO}$ restored pollen germination rates to levels similar to the control (14\%; Figure 3 and Figure 5). Adding $1 \mathrm{mM}$ and $3 \mathrm{mM}$ GSH to the medium containing $0.1 \mathrm{mM}$ BSO increased pollen germination rate to $16 \%$ and 25\%, respectively (Figure 4 and Figure 5). Similar levels were found when $1 \mathrm{mM} \mathrm{GSH}$ and $3 \mathrm{mM} \mathrm{GSH}$ were added to pollen germination media without BSO (21\% and $26 \%$, respectively). The addition of $5 \mathrm{mM}$ GSH to medium containing $0.1 \mathrm{mM}$ BSO decreased pollen germination rates to $5 \%$, which was similar to the germination rate of pollen grown on medium with the addition of $5 \mathrm{mM} \mathrm{GSH}$ (Figure 5). The addition of IAA to the growth medium containing $3 \mathrm{mM}$ and $5 \mathrm{mM}$ GSH did not affect pollen germination and was similar to the germination rate of pollen grown on $3 \mathrm{mM}$ and 5 $\mathrm{mM}$ GSH alone (Figure 5). The addition of higher BSO concentrations (1.5 $\mathrm{mM}$ and $5 \mathrm{mM}$ ) decreased pollen germination rates to $6 \%$ and $4 \%$, respectively (Additional file 4). The addition of $1 \mathrm{mM}$ and $3 \mathrm{mM} \mathrm{GSH}$ to media containing $1.5 \mathrm{mM}$ BSO restored pollen germination rates to $23 \%$ and $10 \%$, respectively. Adding $1 \mathrm{mM} \mathrm{GSH}$

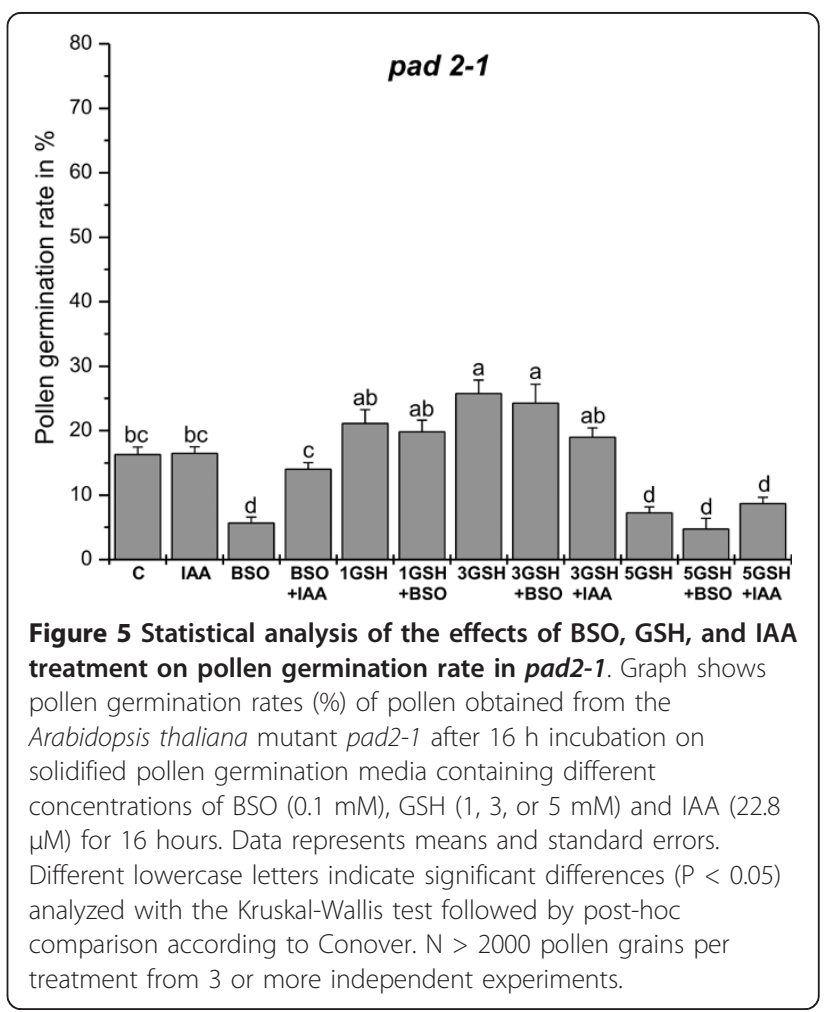


and $3 \mathrm{mM} \mathrm{GSH}$ to media containing $5 \mathrm{mM}$ BSO increased the pollen germination rates of the pad2-1 mutant to $11 \%$ and $6 \%$, respectively (Additional file 4 ).

\section{Glutathione labeling}

Immunogold particles localized to glutathione were found in all cell compartments except cell walls and vacuoles (Figure 6). Gold particle density was much higher in pollen obtained from wildtype plants than in pad2-1 mutants (10.8 and 2.2 gold particles per $\mu \mathrm{m}^{2}$, respectively; Figure 7 and Figure 8). Mitochondria, plastids, nuclei and the cytosol contained equally dense quantities of gold particles bound to glutathione (Figure 6 and Figure 9). Gold particle density was similar in wildtype pollen grains which were allowed to germinate on medium without GSH and BSO (10.8 gold particles per $\mu \mathrm{m}^{2}$ ) and on media containing $1 \mathrm{mM} \mathrm{GSH}$ with and without $0.1 \mathrm{mM} \mathrm{BSO}$ (11.3 and 9.9 gold particles per $\mu \mathrm{m}^{2}$, respectively). An increase in glutathione contents in wildtype pollen between $161 \%$ and $153 \%$ was observed when $3 \mathrm{mM} \mathrm{GSH}$ was added to the media with or without $0.1 \mathrm{mM} \mathrm{BSO}$, respectively (Figure 7). The treatment of pollen grains from Col-0 and the pad2-1 mutant with BSO decreased gold particle density to background levels $\left(<0.1\right.$ gold particles per $\mu \mathrm{m}^{2}$; Figures $6,7,8,9$ ).

Pollen grains from the pad2-1 mutant contained lower glutathione-labeling density ( 2.2 gold particles per $\mu \mathrm{m}^{2}$ ) than wildtype (Figure 8), whereas the addition of $1 \mathrm{mM}$ GSH and $3 \mathrm{mM} \mathrm{GSH}$ to the germination media increased glutathione contents to values similar to pollen grains from wildtype plants $(8.7$ and 29 gold

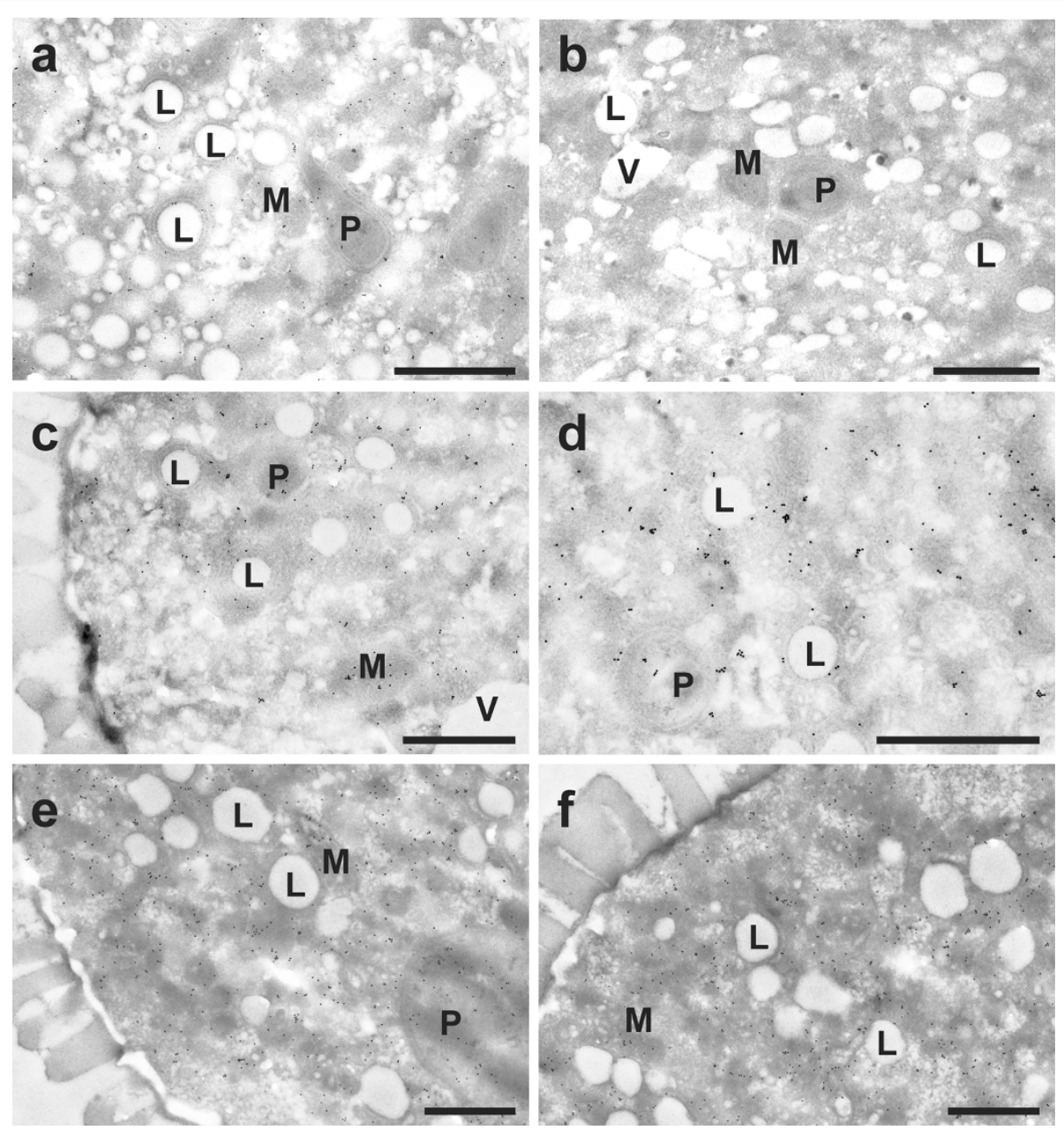

Figure 6 Transmission electron micrographs showing the subcellular distribution of glutathione in Col-0 pollen grains. Gold particles bound to glutathione could be found evenly distributed in plastids (P), mitochondria (M), and the cytosol but not in lipid bodies (L), vacuoles ( $V$ and cell walls of pollen grains obtained from Arabidopsis thaliana accession Col-0. Pollen grains were grown on solidified pollen germination medium for 5 hours with either (a) no GSH and BSO (control), (b) $0.1 \mathrm{mM} \mathrm{BSO}$, (c) $1 \mathrm{mM} \mathrm{GSH}$, (d) $0.1 \mathrm{mM}$ BSO and $1 \mathrm{mM}$ GSH, (e) 3 mM GSH, and (f) $3 \mathrm{mM} \mathrm{GSH}$ and $0.1 \mathrm{mM}$ BSO prior to fixation. Bars $=1 \mu \mathrm{m}$. 


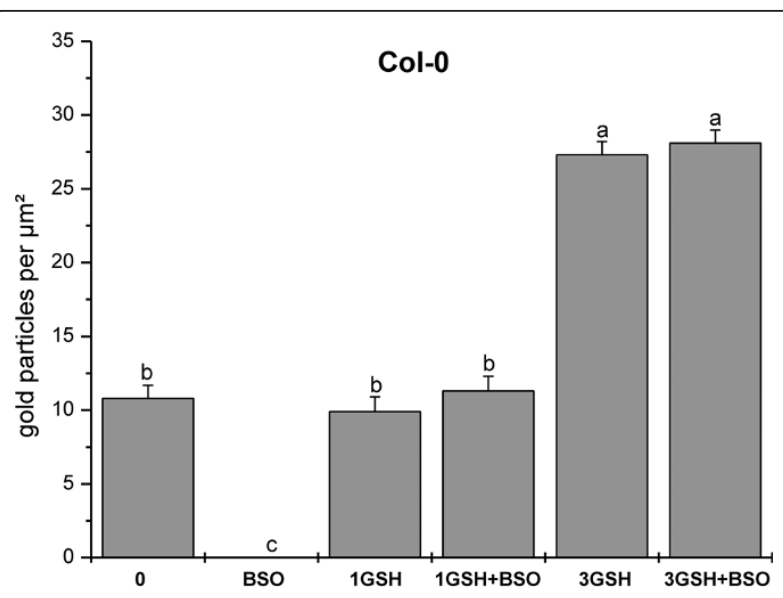

Figure 7 Statistical analysis of the subcellular distribution of glutathione in pollen grains of Col-0. Total amount of gold particles bound to glutathione per $\mu \mathrm{m}^{2}$ in pollen grains of Arabidopsis thaliana accession Col-0. Pollen grains were incubated for 5 hours on solidified pollen germination media containing different concentrations of BSO $(0.1 \mathrm{mM})$ and GSH (1 or $3 \mathrm{mM}$ ) Data represent means and standard errors. Different lowercase letters indicate significant differences $(P<0.05)$ analyzed with the Kruskal-Wallis test followed by post-hoc comparison according to Conover. $N>20$ pollen grains per treatment from 2 independent experiments.

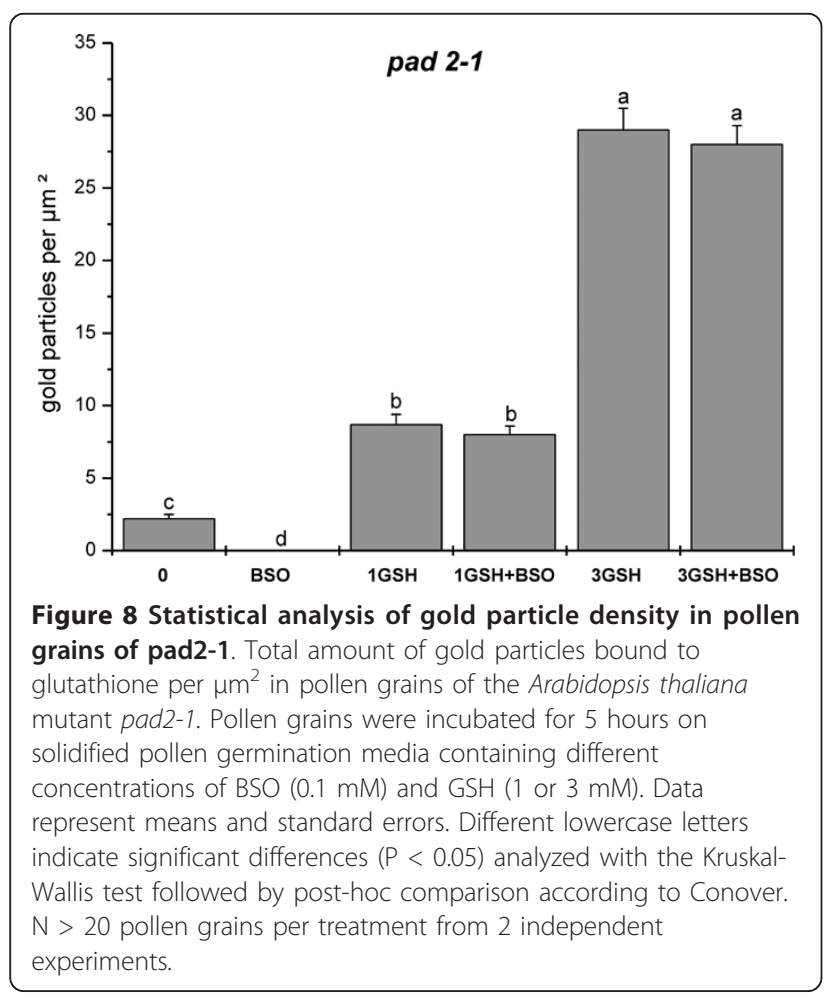

particles per $\mu \mathrm{m}^{2}$, respectively). Similar gold particle densities were reached when $0.1 \mathrm{mM}$ BSO was added to GSH (Figure 8).

\section{Discussion}

The results of this study clearly demonstrate that glutathione synthesis is essential for pollen germination in vitro. Despite negligible levels of GSH1 and GSH2 transcripts occurring in pollen and sperm cells [23,24], glutathione was found to be clearly present and active in the male gametophyte. Pollen germination rates of wildtype pollen, used as controls in the current study (71\%), were similar to those observed in previous studies under similar conditions [35]. Inhibition of glutathione synthesis by $\mathrm{BSO}$ decreased the pollen germination rate to about $5 \%$, which could be correlated with the absence of glutathione specific labeling in our immunogold assays. BSO inhibits the first enzyme (GSH1) of the glutathione synthesis pathway, which leads to a decrease or complete absence of glutathione in leaves [26-31]. In pollen grains of the pad2-1 mutant, in which glutathione synthesis is distorted by a single point mutation in GSH1, decreasing glutathione content to $\sim 20 \%$ of wildtype [32] a similar result is observed. Pollen germination of the pad2-1 mutant was reduced to about $16 \%$, and correlated with an $80 \%$ reduction in glutathione specific immunolabeling when compared to the wildtype. A further decrease of pollen germination rate to $5 \%$ was accomplished by the addition of BSO to the growth media. Similar results have also been observed during germ tube development in Candida albicans. Similarly, strong depletions in GSH contents induced by 1-chloro2,4 dinitrobenzene were correlated with very significant reductions in germ tube formation capacity and severe cell mortality [36]. The addition of $1 \mathrm{mM}$ GSH to growth media containing BSO, could restore pollen germination rate and glutathione specific labeling to values similar to the controls in pollen from both wildtype plants and the pad2-1 mutant. Thus, these results clearly demonstrate that glutathione synthesis and the availability are essential for pollen germination and demonstrate the importance of glutathione not only for plant development but also for pollen germination and tube growth. Additionally, these results showed that pollen grains where glutathione synthesis was inhibited by BSO were able to import glutathione from the growth medium by unknown mechanisms. This could be important considering that glutathione uptake transporters have not been identified yet at the plasma membrane and that negligible transcripts levels of GSH1 and GSH2 were found in pollen and sperm cells [23,24].

The pad2-1 GSH1 point mutant showed a much lower pollen germination rate $(71 \%$ vs. $16 \%$, respectively), which presumably correlates with a much lower 

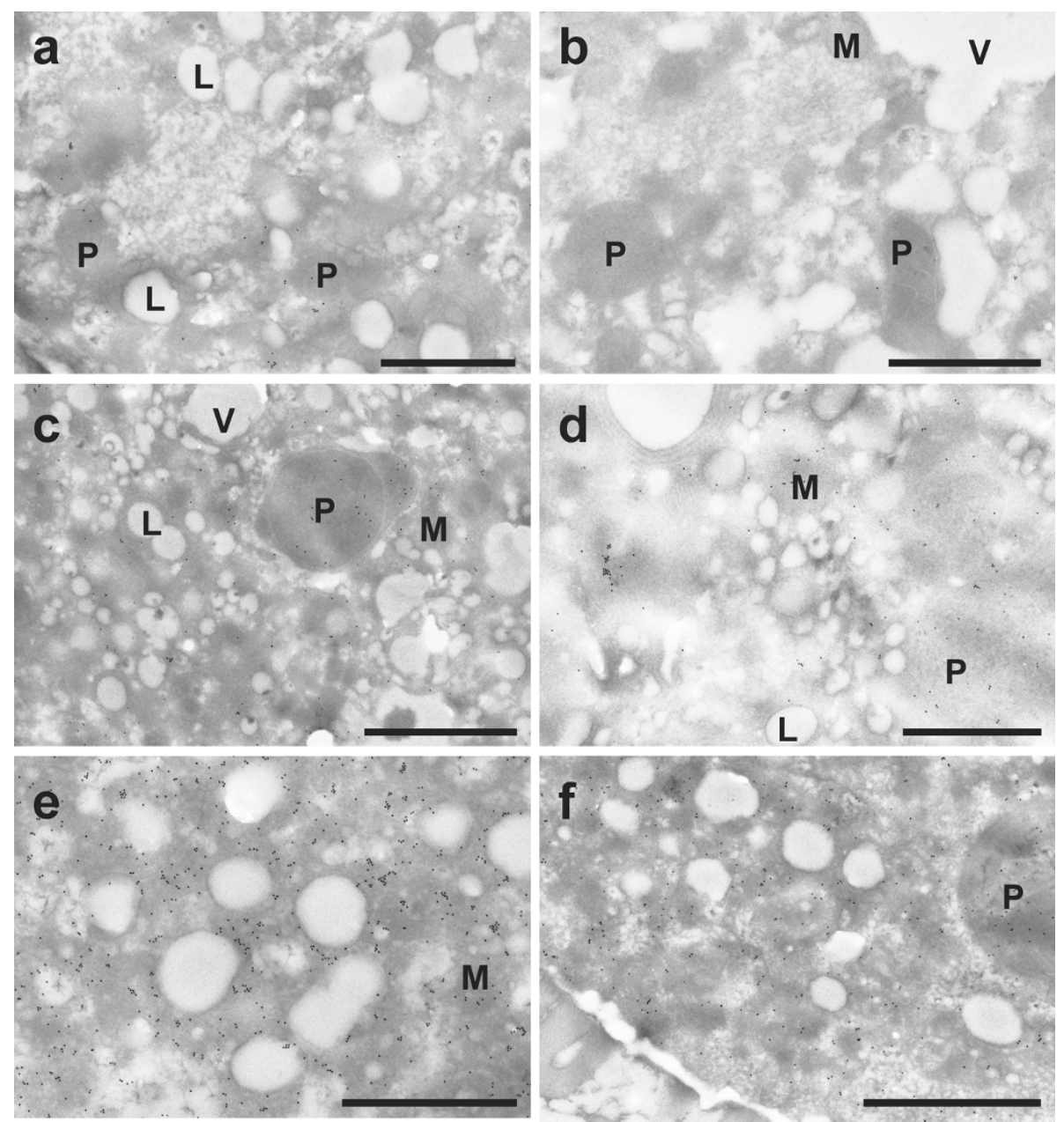

Figure 9 Transmission electron micrographs showing the subcellular distribution of glutathione in pollen grains of pad2-1. Gold particles bound to glutathione could be found evenly distributed in plastids (P), mitochondria (M), and the cytosol but not in lipid bodies (L), vacuoles $(V)$ and cell walls in pollen obtained from the Arabidopsis thaliana mutant pad2-1. Pollen grains were grown on solidified pollen germination medium for 5 hours with either (a) no GSH and BSO (control), (b) $0.1 \mathrm{mM} \mathrm{BSO}$, (c) $1 \mathrm{mM} \mathrm{GSH}$, (d) $0.1 \mathrm{mM} \mathrm{BSO}$ and $1 \mathrm{mM}$ GSH, (e) 3 $\mathrm{mM} \mathrm{GSH}$, and (f) $3 \mathrm{mM} \mathrm{GSH}$ and $0.1 \mathrm{mM} \mathrm{BSO}$ prior to fixation. Bars $=1 \mu \mathrm{m}$.

glutathione content $(-80 \%)$ when compared to the wildtype. As the pad2-1 mutant accumulates only about $20 \%$ glutathione levels of the wildtype [32], these results demonstrate that glutathione contents in pollen grains strongly depend on adequate glutathione availability in the plant. Compartment-specific differences (e.g., accumulation of glutathione in mitochondria), as observed in leaves and roots of the pad2-1 mutants [19], could not be detected in pollen grains where glutathione concentrations were found to be distributed in all typically labelled cell compartments equally. A slightly higher germination rate of pad2-1 pollen (about 25\%) could be accomplished by the addition of $3 \mathrm{mM} \mathrm{GSH}$ to the growth media, which still displayed far below the normal germination rate of wildtype control pollen grains (71\%) and was similar to the germination rate achieved when pollen grains from the wildtype were treated with the same GSH concentration (16\%). The addition of $5 \mathrm{mM}$ GSH decreased pollen germination rate in both wildtype and pad2-1 mutants to $12 \%$ and $6 \%$, respectively, demonstrating that high levels of GSH negatively affect the ability of pollen grains to germinate. It has been demonstrated recently that the treatment of roots with high levels of GSH can cause severe ultrastructural alterations [31,37]. Additionally, it has been demonstrated that in GSH-overexpressing tobacco plants, elevated glutathione biosynthetic capacity in the chloroplasts paradoxically increased oxidative stress, leading to severe ultrastructural alterations within chloroplasts and to their ultimate degeneration, eventuating in the death of the cell [38]. Even though such ultrastructural changes have not been observed during the present study, treatment of pollen grains with high 
levels of GSH (e.g. 3 and 5 mM GSH) could potentially inhibit pollen germination (e.g., by changing the internal redox status). The application of BSO together with IAA, one of the most important hormones regulating pollen tube growth $[33,34]$ restored the rate of pollen germination in the pad2-1 mutant to about 14\%, which was similar to levels achieved by untreated pollen of the pad2-1 mutant used as control. The same experiment restored the rate of pollen germination in the wildtype of BSO-treated pollen to over $60 \%$. Thus, these results demonstrate that low glutathione levels in pollen grains of the pad2-1 mutant must have altered their ability to germinate in the long term. It has been demonstrated recently that the accumulation of ROS in mitochondria was found to be critical for proper pollen development, as sterile pollen grains showed decreased pools of ATP and NADH and lower activity of mitochondria DNA [25]. As glutathione is essential for the detoxification of $\mathrm{ROS} / \mathrm{H}_{2} \mathrm{O}_{2}$ in plants it seems likely that the low germination rates of pollen grains from the pad2-1 mutants were caused by low glutathione levels in the plant and pollen grains during pollen development in the stamen. Nevertheless, pollen grains are thought to possess resistance against or ability to downregulate production of stigma-associated $\mathrm{ROS} / \mathrm{H}_{2} \mathrm{O}_{2}$ (e.g. by antioxidants) in order to germinate on and penetrate through the stigma [39]. As pollen germination of pad2-1 pollen grains could be only partly increased by the addition of 1 and 3 mM GSH (from $14 \%$ to $16 \%$ and 25\%, respectively) but never reached rates of the wildtype (71\%) these results also suggest that insufficient glutathione is present without activity of GSH1 to permit normal rates of germination. Thus, we can conclude that sufficient glutathione contents are required during pollen development and also during pollen germination for proper pollen germination of pollen from the pad2-1 mutant.

Since a reduction of root growth induced by the depletion of GSH is caused by the inhibition of auxin transport $[40,41]$, we tested if inhibited pollen germination by BSO can be restored by treatment with IAA, which is one of the most important plant hormones for pollen tube growth [33,34]. Results of this study demonstrated that the application of BSO together with IAA diminished the deleterious effects of BSO and led to pollen germination rates similar to that of control pollen. The addition of IAA alone or together with GSH did not have such affects. Thus, we can conclude that glutathione depletion in pollen grains triggered disturbances in auxin metabolism which are linked with inhibition of pollen germination induced by BSO treatment.

\section{Conclusions}

Summing up, it can be concluded that glutathione synthesis is essential for pollen germination in vitro. Additionally, it was demonstrated that low glutathione levels in the pad2-1 mutant decreased their ability to germinate caused by disturbances most probably during pollen development. The mechanisms behind the reduction of pollen germination induced by glutathione depletion could be correlated with disturbances in auxin metabolism which still have to be explored in more detail.

\section{Methods}

\section{Plant material}

After stratification for 4 days at $4^{\circ} \mathrm{C}$, seeds of Arabidopsis thaliana [L.] Heynh. Ecotype Columbia (Col-0) originally obtained from the European Arabidopsis stock centre (NASC; Loughborough, UK), and the glutathione deficient mutant line pad 2-1 were grown on soil in greenhouse conditions with approximately $16 / 8 \mathrm{~h}$ day/night photoperiod. Day and night temperatures were $22^{\circ} \mathrm{C}$ and $18^{\circ} \mathrm{C}$, respectively. The relative humidity was $60 \%$ and the plants were kept at $100 \%$ relative soil water content. Light intensity varied between $120-150 \mu \mathrm{mol} \mathrm{m} \mathrm{m}^{-2} \mathrm{~s}^{-1}$.

\section{Determination of pollen germination}

Four to six weeks after flowering, pollen was harvested from about 20 different plants for each experiment and transferred onto pollen germination medium mounted on glass slides, which were kept and prepared in moist chambers at $22^{\circ} \mathrm{C}$. Pollen germination medium was always prepared fresh with double distilled water and contained $5 \mathrm{mM} \mathrm{CaCl}_{2}, 1 \mathrm{mM} \mathrm{MgSO}_{4}, 5 \mathrm{mM} \mathrm{KCl}, 0.01$ $\mathrm{mM} \mathrm{H}_{3} \mathrm{BO}_{3}, 10 \%$ sucrose and $1.5 \%$ agarose. The $\mathrm{pH}-$ value was adjusted to 7.5 with a $1 \mathrm{M} \mathrm{NaOH}$ solution. In addition, different concentrations of reduced glutathione (GSH), buthionine sulfoximine (BSO), and indole-3acetic acid (IAA) were added to the germination media. Pollen germination media contained either (a) no GSH and BSO (control), (b) $22.8 \mu \mathrm{M}$ IAA, (c) $0.1 \mathrm{mM}$ BSO, (d) $0.1 \mathrm{mM}$ BSO and $22.8 \mu \mathrm{M}$ IAA, (e) $1 \mathrm{mM}$ GSH, (f) $1 \mathrm{mM}$ GSH and $0.1 \mathrm{mM}$ BSO, (g) $3 \mathrm{mM} \mathrm{GSH}$, (h) 3 $\mathrm{mM}$ GSH and $0.1 \mathrm{mM}$ BSO, (i) $3 \mathrm{mM}$ GSH and 22.8 $\mu \mathrm{M}$ IAA, (j) $5 \mathrm{mM}$ GSH, (k) $5 \mathrm{mM}$ GSH and $0.1 \mathrm{mM}$ $\mathrm{BSO}$, and (l) $5 \mathrm{mM}$ GSH and $22.8 \mu \mathrm{M}$ IAA. In preliminary studies additional concentrations of BSO and GSH were tested (1.5 mM BSO and $5 \mathrm{mM}$ BSO with or without the addition of $1 \mathrm{mM}$ and $3 \mathrm{mM} \mathrm{GSH}$ ) in order to evaluate the ideal BSO and GSH concentrations for the proposed experiments. IAA concentration was chosen according to previous studies which demonstrated that the addition of $22.8 \mu \mathrm{M}\left(4 \mathrm{mg} \mathrm{L}^{-1}\right)$ IAA stimulated pollen tube growth most effectively [33,34]. Therefore, 100 mM stock solutions of GSH, BSO and IAA respectively, were prepared and small aliquots of these solutions were added to the pollen germination media to reach the final concentration of GSH, BSO, and IAA. The pHvalue of the media was adjusted to 7.5 with a $1 \mathrm{mM}$ 
$\mathrm{NaOH}$-solution. After transferring pollen on the germination media, grains were allowed to germinate in the dark at $22^{\circ} \mathrm{C}$ in a temperature controlled incubator. Slides were either examined for pollen germination rates under a Zeiss Stemi SV11 or an Olympus Provis AX 70 microscope (Olympus, Life and Material Science Europa GmbH, Hamburg, Germany) 16 hours later. Digital images were taken of several randomly chosen areas on the slides containing pollen grains and the amount of pollen that germinated was determined with the help of the image analysis software Olympus Cell D (Olympus, Life and Material Science Europa GmbH, Hamburg, Germany).

\section{Sample preparation for electron microscopy}

Pollen grains were allowed to germinate on solidified pollen germination media containing different concentrations of GSH and BSO for 5 hours. Then they were covered with $2.5 \%$ low melting agarose and transferred in the fixative solution after the agarose was solidified (within 30 seconds). For electron microscopical analysis pollen grains were fixed in $2.5 \%$ paraformaldehyde and $0.5 \%$ glutaraldehyde in $0.06 \mathrm{mM}$ phosphate buffer $(\mathrm{pH} 7.5)$ containing $10 \%$ sucrose for 45 minutes. Samples were washed in buffer 4 times 15 minutes and dehydrated in increasing concentrations of acetone $(50 \%, 70 \%$, and $90 \%$ ) for 2 times 10 minutes for each step. Infiltration was carried out with increasing concentrations of LR-White resin $(30 \%, 50 \%$, and $70 \%$ ) mixed with $90 \%$ acetone with a minimum of 3 hours per step. Samples were then infiltrated with 100\% LR-White resin for 4 hours and embedded in fresh resin for 48 hours at $50^{\circ} \mathrm{C}$. Ultrathin sections $(80 \mathrm{~nm})$ were cut with a Reichert Ultracut S ultramicrotome (Leica, Microsystems, Vienna, Austria).

\section{Cytohistochemical investigations}

Immunogold labeling of glutathione was conducted using ultrathin sections mounted on coated nickel grids and labeled with the Leica EM IGL automated immunogold labeling system (Leica, Microsystems, Vienna, Austria) according to Zechmann et al. and Zechmann and Müller $[19,20]$. For cytohistochemical analysis, samples were blocked with $2 \%$ bovine serum albumin (BSA) in phosphate buffered saline (PBS, pH 7.2) for $20 \mathrm{~min}$ at room temperature. The sections were then treated with the primary antibody against glutathione (anti-glutathione rabbit polyclonal immunoglobulinG [IgG]; Millipore Corp., Billerica, MA, U.S.A.) diluted 1:50 in PBS for $2 \mathrm{~h}$. After short rinses in PBS (3 times $5 \mathrm{~min}$ ) the samples were incubated with a $10 \mathrm{~nm}$ gold-conjugated secondary antibody (goat anti rabbit IgG; British BioCell International, CardiV, UK) diluted 1:50 in PBS for $90 \mathrm{~min}$. After short washes in PBS (3 times $5 \mathrm{~min}$ ) and distilled water (2 times $5 \mathrm{~min}$ ) labeled grids were either immediately observed in a Philips CM10 transmission electron microscope or post stained with uranyl-acetate ( $2 \%$ dissolved in double distilled water) for $15 \mathrm{~s}$. Post staining with uranyl acetate was applied to facilitate the distinction of different cell structures enabling a clearer identification of the investigated organelles.

\section{Quantitative analysis of immunogold labeling}

Micrographs of randomly photographed immunogold labeled sections of pollen grains were digitized and gold particles were counted automatically using the software package Cell D using the particle analysis tool (Olympus, Life and Material Science Europa GmbH, Hamburg, Germany). A minimum of 20 sectioned pollen grains from two independent experiments were analyzed for gold particle density. The obtained data were recorded as the number of gold particles per $\mu \mathrm{m}^{2}$. For all statistical analyses the non-parametric Kruskal-Wallis test followed by a post-hoc comparison according to Conover was used. $\mathrm{P}<0.05$ was considered as significant.

\section{Additional material}

\begin{abstract}
Additional file 1: $\gamma$-glutamyl-cysteine synthetase (At4g23100), reported by available Affymetrix $24 \mathrm{~K}$ Arabidopsis genomic microarray data at Genevestigator.

Additional file 2: Glutathione synthetase (At5g27380), reported by available Affymetrix $24 \mathrm{~K}$ Arabidopsis genomic microarray data at Genevestigator

Additional file 3: Effect of BSO (buthionine sulfoximine) and GSH (reduced glutathione) treatment on pollen germination rate. Graph shows Arabidopsis thaliana accession Col-0 pollen germination rates (\%) after $16 \mathrm{~h}$ incubation on solidified pollen germination media containing different concentrations of BSO (1.5 mM) and GSH (1 or $3 \mathrm{mM}$ ) for 16 hours. Data represent means and standard errors. Different lowercase letters indicate significant differences $(P<0.05)$ analyzed with the Kruskal-Wallis test followed by post-hoc comparison according to Conover. $\mathrm{N}>2000$ pollen grains per treatment from 3 or more independent experiments.

Additional file 4: Effect of BSO (buthionine sulfoximine) and GSH (reduced glutathione) treatment on pollen germination rate. Graph shows pollen germination rates (\%) of pollen obtained from the Arabidopsis thaliana mutant pad2-1 after $16 \mathrm{~h}$ incubation on solidified pollen germination media containing different concentrations of BSO (1.5 $\mathrm{mM}$ ) and GSH (1 or $3 \mathrm{mM}$ ) for 16 hours. Data represent means and standard errors. Different lowercase letters indicate significant differences $(P<0.05)$ analyzed with the Kruskal-Wallis test followed by post-hoc comparison according to Conover. N > 2000 pollen grains per treatment from 3 or more independent experiments.
\end{abstract}

\section{Abbreviations}

ATP: adenosine triphosphate; BSO: buthionine sulfoximine; BSA: bovine serum albumin; IAA: indole-3-acetic acid; GSH: reduced glutathione; GSSG: oxidized glutathione; PBS: phosphate buffered saline; ROS: reactive oxygen species.

\section{Acknowledgements}

This work was supported by the Austrian Science Fund (FWF, P20619 and P22988 to B.Z.). 


\section{Author details}

'University of Graz, Institute of Plant Sciences, Schubertstrasse 51, 8010 Graz, Austria. ${ }^{2}$ Graz University of Technology, Institute for Electron Microscopy and Fine Structure Research, Steyrergasse 17, 8010 Graz, Austria. ${ }^{3}$ University of Oklahoma, Department of Botany and Microbiology, Samuel Roberts Noble Electron Microscopy Laboratory, 770 Van Vleet Oval, Norman, Oklahoma, 73019, USA.

\section{Authors' contributions}

BZ conceived of the study and participated in its design and coordination, carried out the electron and light microscopical work and drafted the manuscript. BK participated in electron and light microscopical studies, and performed quantitative and statistical analysis of the data. SDR participated in the design of the study and its coordination and helped to draft the manuscript. All authors read and approved the final manuscript.

Received: 18 December 2010 Accepted: 26 March 2011

Published: 26 March 2011

\section{References}

1. Foyer $\mathrm{CH}$, Noctor $\mathrm{G}$ : Redox regulation and photosynthetic organisms: Signaling, acclimation, and practical implications. Antioxid Redox Signal 2009, 11:861-905.

2. Edwards R, Brazier-Hicks M, Dixon DP, Cummins I: Chemical manipulation of antioxidant defences in plants. Adv Bot Res 2005, 42:1-32.

3. DeRidder BP, Goldsbrough PB: Organ-specific expression of glutathione $\mathbf{S}$ transferases and the efficacy of herbicide safeners in Arabidopsis. Plant Physiol 2006, 140:167-175.

4. Zawoznik MS, Groppa MD, Tomaro ML, Benavides MP: Endogenous salicylic acid potentiates cadmium-induced oxidative stress in Arabidopsis thaliana. Plant Sci 2007, 173:190-197.

5. Ammar WB, Mediouni C, Tray B, Ghorbel MH, Jemal F: Glutathione and phytochelatin contents in tomato plants exposed to cadmium. Biol Plant 2008, 52:314-320.

6. DalCorso G, Farinati S, Maistri S, Furini A: How plants cope with cadmium: Staking all on metabolism and gene expression. J Integr Plant Biol 2008, 50:1268-1280.

7. Dučić T, Maksimović V, Radotić K: Oxalate oxidase and non-enzymatic compounds of the antioxidative system in young Serbian spruce plants exposed to cadmium stress. Arch Bio Sci, Belgrade 60:67-76.

8. Nocito FF, Espen L, Crema B, Cocucci M, Sacchi GA: Cadmium induces acidosis in maize root cells. New Phytol 2008, 179:700-711.

9. Dixon DP, Skipsey M, Grundy NM, Edwards R: Stress-induced protein Sglutathionylation in Arabidopsis. Plant Physiol 2005, 138:2233-2244.

10. Hurd TR, Filipovska A, Costa NJ, Dahm CC, Murphy MP: Disulphide formation in mitochondrial protein thiols. Biochem Soci Transact 2005, 33:1390-1393

11. Hurd TR, Costa NJ, Dahm CC, Beer SM, Brown ST, Filipovska A, Murphy MP: Glutathionylation of mitochondrial proteins. Antioxid Redox Signal 2005, 7:999-1010.

12. Cheng JC, Seeley KA, Sung ZR: RML1 and RML2, Arabidopsis genes required for cell proliferation at the root tip. Plant Physiol 1995, 107:365-376.

13. Vernoux T, Wilson RC, Seeley KA, Reichheld JP, Muroy S, Brown S, Maughan SC, Cobbett CS, Van Montagu M, Inze D, May MJ, Sung ZR: The root meristemless/cadmium sensitive2 gene defines a glutathione-dependent pathway involved in initiation and maintenance of cell division during postembryonic root development. Plant Cell 2000, 12:97-110.

14. Cairns NG, Pasternak M, Wachter A, Cobbett CS, Meyer AJ: Maturation of Arabidopsis seeds is dependent on glutathione biosynthesis within the embryo. Plant Physiol 2006, 141:446-455.

15. Kranner I, Beckett RP, Wornik S, Zorn M, Pfeifhofer HW: Revival of a resurrection plant correlates with its antioxidant status. Plant J 2002, 31:13-24.

16. Kranner I, Birtic S, Anderson KM, Pritchard HW: Glutathione half-cell reduction potential: $A$ universal stress marker and modulator of programmed cell death. Free Rad Biol Med 2006, 40:2155-2165.

17. Queval G, Issakidis-Bourguet E, Hoeberichts FA, Vandorpe M, Gakiere B, Vanacker H, Miginiac-Maslow M, Van Breusegem F, Noctor G: Conditional oxidative stress responses in the Arabidopsis photorespiratory mutant cat2 demonstrate that redox state is a key modulator of daylength- dependent gene expression and define photoperiod as a crucial factor in the regulation of H2O2-induced cell death. Plant J 2007, 52:640-657.

18. Wachter A, Wolf $\mathrm{S}$, Steininger H, Bogs J, Rausch T: Differential targeting of GSH1 and GSH2 is achieved by multiple transcription initiation: implications for the compartmentation of glutathione biosynthesis in the Brassicaceae. Plant J 2005, 41:15-30.

19. Zechmann B, Mauch F, Sticher L, Müller M: Subcellular immunocytochemical analysis detects the highest concentrations of glutathione in mitochondria and not in plastids. J Exp Bot 2008, 59:4017-4027.

20. Zechmann B, Müller M: Subcellular compartmentation of glutathione in dicotyledonous plants. Protoplasma 2010, 246:15-24.

21. Höller K, Király L, Künstler A, Müller M, Gullner G, Fattinger M, Zechmann B: Enhanced glutathione metabolism is correlated with sulfur induced resistance in Tobacco mosaic virus-infected genetically susceptible Nicotiana tabacum plants. Mol Plant Microbe Interact 2010, 23:1448-1459.

22. Queval G, Jaillard D, Zechmann B, Noctor G: Increased intracellular $\mathrm{H}_{2} \mathrm{O}_{2}$ availability preferentially drives glutathione accumulation in vacuoles and chloroplasts. Plant, Cell Environ

23. Borges F, Gomes G, Gardner R, Moreno N, McCormick S, Feijo JA, Becker JD: Comparative transcriptomics of Arabidopsis thaliana sperm cells. Plant Physiol 2008, 148:1168-1181.

24. Honys D, Twell D: Comparative analysis of the Arabidopsis pollen transcriptome. Plant Physiol 2003, 132:640-652

25. Wan C, Li S, Wen L, Kong J, Wang K, Zhu W: Damage of oxidative stress on mitochondria during microspores development in Honglian CMS line of rice. Plant Cell Rep 2007, 26:373-382.

26. Müller M, Tausz M, Grill D: Histochemical tracing of glutathione by fluorescence microscopy and image analysis system in living plant cells. In Different pathways through life-Biochemical aspects of plant biology and medicine. Edited by: Denke A, Dornisch K, Fleischmann F, Graßmann J, Heiser I, Hippeli S, Oßwald W, Schempp H. Munich: Lincom Europa; 1999:189-197.

27. Gullner G, Dodge AD: Accumulation of glutathione in pea leaf discs exposed to the photooxidative herbicides acifluorfen and 5aminolevulinic acid. J Plant Physiol 2000, 156:111-117.

28. Meyer AJ, Fricker MD: Control of demand-driven biosynthesis of glutathione in green Arabidopsis suspension culture cells. Plant Physiol 2002, 130:1927-1937.

29. Hartmann T, Hönicke P, Wirtz M, Hell R, Rennenberg H, Kopriva S: Regulation of sulphate assimilation by glutathione in poplars (Populus tremula X $P$. alba) of wild type and overexpressing $\mathrm{Y}$-glutamylcysteine synthetase in the cytosol. J Exp Bot 2004, 55:837-845.

30. Senda K, Ogawa K: Induction of PR-1 accumulation accompanied by runaway cell death in the $\mid s d 1$ mutant of Arabidopsis is dependent on glutathione levels but independent of the redox state of glutathione. Plant Cell Physiol 2004, 45:1578-1585.

31. Zechmann B, Müller M, Zellnig G: Intracellular adaptations of glutathione content in Cucurbita pepo (L.) induced by reduced glutathione and buthionine sulfoximine treatment. Protoplasma 2006, 227:197-209.

32. Parisy V, Poinssot B, Owsianowski L, Buchala A, Glazebrook J, Mauch F: Identification of PAD2 as a c-glutamylcysteine synthetase highlights the importance of glutathione in disease resistance of Arabidopsis. Plant $J$ 2007, 49:159-172.

33. Wu J, Lin $Y$, Zhang $X L$, Pang DW, Zhao J: IAA stimulates pollen tube growth and mediates the modification of its wall composition and structure in Torenia fournieri. J Exp Bot 2008, 59:2529-2543.

34. Wu J, Qin Y, Zhao J: Pollen tube growth is affected by exogenous hormones and correlated with hormone changes in styles in Torenia fournieri L. Plant Growth Regul 2008, 55:137-148.

35. Boavida LC, McCormick S: Temperature as a determinant factor for increased and reproducible in vitro pollen germination in Arabidopsis thaliana. Plant J 2007, 52:570-582

36. González-Párraga P, Marín FR, Argüelles JC, Hernández JA: Correlation between the intracellular content of glutathione and the formation of germ-tubes induced by human serum in Candida albicans. Biochim Biophys Acta 2005, 1722:324-330.

37. Zellnig G, Tausz M, Pesec B, Grill D, Müller M: Effects of glutathione on thiol redox systems, chromosomal aberrations, and the ultrastructure of meristematic root cells of Picea abies (L.) Karst. Protoplasma 2000, 212:227-235 
38. Creissen G, Firmin J, Fryer M, Kular B, Leyland N, Reynolds H, Pastori G, Wellburn F, Baker N, Wellburn A, Mullineaux P: Elevated glutathione biosynthetic capacity in the chloroplasts of transgenic tobacco plants paradoxically causes increased oxidative stress. Plant Cell 1999,

11:1277-1291

39. McInnis SM, Emery DC, Porter R, Desikan R, Hancock JT, Hiscock SJ: The role of stigma peroxidases in flowering plants: insights from further characterization of a stigma-specific peroxidase (SSP) from Senecio squalidus (Asteraceae). J Exp Bot 2006, 57:1835-1846.

40. Bashandy T, Guilleminot J, Vernoux T, Caparros-Ruiz D, Ljung K, Meyer Y, Reichheld JP: Interplay between the NADP-linked thioredoxin and glutathione systems in Arabidopsis auxin signaling. Plant Cell 2010, 22:376-391.

41. Koprivova A, Mugford ST, Kopriva S: Arabidopsis root growth dependence on glutathione is linked to auxin transport. Plant Cell Rep 2010, 29:1157-1167.

doi:10.1186/1471-2229-11-54

Cite this article as: Zechmann et al:: Glutathione synthesis is essential for pollen germination in vitro. BMC Plant Biology 2011 11:54.

\section{Submit your next manuscript to BioMed Central} and take full advantage of:

- Convenient online submission

- Thorough peer review

- No space constraints or color figure charges

- Immediate publication on acceptance

- Inclusion in PubMed, CAS, Scopus and Google Scholar

- Research which is freely available for redistribution

Submit your manuscript at www.biomedcentral.com/submit 